\title{
The Health Implications of Plastic Bioaccumulation and The Potential to Enhance Biotransformation Using Herbal Medicine and Nutritional Supplements
}

\author{
Carina Harkin* \\ Independent Researcher, University College Cork, Ireland
}

*Corresponding author: Carina Harkin, Independent researcher, University College Cork, Ireland.

Received Date: January 14, 2020

Published Date: February 27, 2020

\begin{abstract}
Plastic is ubiquitous with recent studies having highlighted that plastic is in bottled and tap water and food products including honey, sugar and beer. 3-10 tonnes are estimated to fall on Paris per year. Plastic has recently been shown to be a vector for heavy metal contamination and to cross the blood-brain barrier (BBB). Global concern regarding the health implications is mounting, with the World Health Organisation (WHO) having conducted a risk assessment review of plastics. Whilst knowledge gaps exist, we remain to eat, drink and inhale plastic without knowing what harm it is potentially causing. This paper discusses the scale of global microplastic contamination, the sources and routes of microplastic contamination including inhaling and ingesting plastics, and the potential health implications of plastic bioaccumulation. Research into biotransformation is new and evolving. This paper looks at how plastic is bio transformed and the potential pharmacognostical approaches that have the potential to maximize plastic biotransformation. This paper discusses what is known about how plastic is bio transformed by Phase I cytochrome P450 enzyme group modification and Phase II glutathione, sulphation, glucuronidation and glycine conjugation pathways, and the importance of supporting endogenous antioxidants to assist plastic biotransformation. The paper specifically discusses what is known about how ingested plastics including phthalates and bisphenol A (BPA), and inhaled plastics, including dioxins and furans are bio transformed by these processes and what herbal medicine and nutritional supplementation may maximise plastic biotransformation and address plastic bioaccumulation.
\end{abstract}

Keywords: Plastic bioaccumulation; Plastic biotransformation; Microplastic; Nano plastic; Microplastics in drinking-water; Microplastic exposure and impacts on human health; Complementary and alternative medicine (CAM); Herbal medicine; Nutritional Supplements; Pharmacognosy

Abbreviations: Acetyl-Coa: Acetyl Coenzyme A; ALS: Amyotrophic Lateral Sclerosis; ADHD: Attention Deficit Hyperactivity Disorder; BPA: Bisphenol A; BBB: Blood-Brain Barrier; CDG: Caclium D-Glucarate; CAT: Catalase; CDC: Centers For Disease Control And Prevention; CD: Cluster Of Differentiation; CAM: Complementary And Alternative Medicine; Cuzn-SOD: Copper-Zinc SOD; CYP450: Cytochrome P450; DDT: Dichlorodiphenyltrichloroethane; DINP: Diisononyl Phthalate; DIDP: Diisodecyl Phthalate; EDCS: Endocrine Disrupting Chemicals; FSAI: Food Safety Authority Of Ireland; GSH: Glutathione; GPX: Glutathione Peroxidase; GR: Glutathione Reductase; GST: Glutathione S-Transferase; GST Family: Glutathione S-Transferases; GMIT: Galway-Mayo Institute Of Technology; GNRH: Gonadotropin-Releasing Hormone; HSE: Health Service Executive; HPA: Hypothalamic-Pituitary Axis; LGBTQI: Lesbian, Gay, Bisexual, Transgender, Queer Or Questioning And Intersex; BZIP: Leucine Zipper; Mn-SOD: Manganese SOD; MFO: Mixed-Function Oxidase Enzyme; NAC: N-Acetylcysteine; NHANES: National Health And Nutrition Examination Survey; NATS: N-Terminal Acetyltransferases; NDDS: Neurodevelopmental Disorders; NDGS: Neurodegenerative Diseases; NRF2: Nuclear Factor-Erythroid-2-Related Factor 2; PCOS: Polycystic Ovary Syndrome; POPS: Persistent Organic Pollutants; PTS: Persistent Toxic Substances; PAHS: Polycyclic Aromatic Hydrocarbons; PCBS: Polychlorinated Biphenyls; PETE: Polyethylene Terephthalate; SAM-E: S-Adenosyl-L-Methionine; SFN: Sulforaphane; SOD: Superoxide Dismutase; TCR: T-Cell Receptor; TCDD: Tetrachlorodibenzo-P-Dioxin; TEQ: Toxic Equivalent; T2D: Type 2 Diabetes; US: United States; UDP: Uridine Diphosphate; UDPGA: Uridine Diphsphate Glucuronic Acid; UGT: UDP-Glucuronosyltransferase; WHO: World Health Organisation

\section{Background}

Plastic is a crude oil product a non-renewable energy source [1]

The largest global consumer of oil is the United States (US) military, consuming 100 million barrels of oil per year [2]. Despite overwhelming evidence of carbon-fuelled climate change and billions in subsidies for alternative technologies, global oil consumption will reach 100 million barrels per day, more than twice what it was 50 years ago, with no sign of abating [3]. The US alone uses 330 million barrels of oil per year in plastics production alone, [4] three times the US military use. 


\section{The scale of microplastic contamination is staggering}

An estimated 8 million tons of plastic enters our oceans each year. Microplastics are omnipresent in marine waters, from deep ocean sediments to polar icecaps [5].

\section{Microplastics contain and absorb toxic chemicals}

Microplastics are a vector for heavy metal contamination from the marine environment [6,7]. Microplastics attract harmful pathogenic bacteria in sewage and contain and absorb toxic chemicals. More than 50 persistent organic pollutants (POPs), specifically polychlorinated biphenyls (PCBs) and polycyclic aromatic hydrocarbons (PAHs) are found in the five most common types of plastic [8]. POPs are also called persistent toxic substances (PTS) [9].

\section{Plastic in Tap Water Globally}

Billions of people are drinking water contaminated by plastic particles with $83 \%$ of samples found to be polluted. The US had highest contamination rate, at $94 \%$, with plastic fibres found in tap water at Congress buildings, ironically the US EPA headquarters and Trump Tower in New York. Lebanon and India had next highest rates. European nations including UK, Germany and France had lowest contamination rate at $72 \%$. The average number of fibres found in each $500 \mathrm{ml}$ sample ranged from 4.8 in the US to 1.9 in Europe [10,11]. An Irish study (June 2017) found microplastic contamination in a handful of tap water and well samples "We don't know what the health impact is and we should follow the precautionary principle so we can find out what the real risks are," said Dr Anne Marie Mahon at the Galway-Mayo Institute of Technology (GMIT) [12].

\section{Plastic in Bottled Water Globally}

The Orb study (Orb Media U.S-based non-profit journalism organisation) tested 259 bottles from 19 locations in 9 countries across 11 different brands were found to contain on average 325 plastic pieces for every liter of water. Scientists used Nile red dye to fluoresce plastic particles in the water, developed by Dr Andrew Mayes, University of East Anglia scientist. Nestlé Pure Life was worst offender; concentrations as high as 10,000 plastic pieces per liter. Of 259 bottles tested, only 17 were plastic free [13]. The contamination is said to be partially coming from packaging and/ or bottling process [14]. The most common plastic fragment was polypropylene plastic used to make bottle caps. Polypropylene is number 5 in triangle and considered safe. The study was not published in a journal, nor has been peer reviewed. A second unrelated Story of Stuff Study examined 19 bottled water brands in the US, also found plastic microfibers were widespread. Plastic fibers in bottled water brands are twice as high as those found in tap water [15]. See (Appendix) for brands Orb Media and Story of Stuff tested.

\section{Plastic Water Bottles}

Plastic water bottles are made from polyethylene terephthalate (PETE recycling code 1). This symbol is normally also found in soft drinks. PETE does not contain BPA/Phthalates, but studies find the endocrine disrupting chemical (EDC) antimony, a toxic phthalate 'plasticiser' used to make plastics flexible, leaches from PET bottles placed in heat for prolonged periods (16). Reusable plastic drinking water bottles are or more generally now, were made from polycarbonate (recycling code 7). Polycarbonate is made of BPA [17]. Investigations show in some cases, BPA-free PETE containers might leach of estrogen like chemicals [18].

\section{Sources of Environmental Microplastic}

\section{Washing acrylic, polyester and nylon}

Plastic derived, acrylic, polyester and nylon persist in the environment. Synthetic clothing that ends up in landfill soaks through the land, into the water table and into our drinking water. Alternatively, it ends up in our sea and evaporates into our clouds and back into our drinking water. One truck load of used clothes goes to landfill every second. One truckload of plastic enters the sea every second. By 2050 scientists estimate there will be more plastic in the sea than fish [19]. Acrylics are by far the worst offender. When acrylics are washed in washing machines, the average load of household washing shed 750,000 microplastics per wash, 5 times more than polyester-cotton. When drying synthetics, we are venting microplastic straight into the atmosphere [20,21].

\section{Burning plastics}

Burring plastics releases endocrine disrupting cancer causing dioxins and furans the most toxic chemicals known to humankind [22].

\section{Human sludge}

A 2017 study for the Environmental Protection Agency (EPA) co-written by Dr Anne Marie Mahon from the Marine from the Freshwater Research Centre, Galway-Mayo Institute of Technology (GMIT) identified sludge spreading and the washing of plastic by the recycling industry as significant sources of environmental microplastics. It estimated that at least a billion microplastic particles are spread on Irish farmland each year (not all farms acquire and spread sludge) [23].

\section{Plastic in teabags}

A recent study indicated that steeping a single plastic teabag at a brewing temperature of $\left(95^{\circ} \mathrm{C}\right)$ releases approximately 11.6 billion microplastics and 3.1 billion nanoplastics into a single cup of tea. The composition of the released particles is matched to the original teabags (nylon and PETE). A toxicity assessment performed by the researchers showed that exposure to the plastic particles released 
from the teabags caused dose-dependent detrimental behavioral and developmental health effects [15]. Non-biodegradable plastic contains teabags have been added to the municipal compost for decades.

\section{Extent of Plastic Contamination in Food and Air}

\section{Plastic in beer, salt and well water}

A German study found plastic fibers and fragments were found in all 24 beer brands tested, as well as honey and sugar. The study concluded the average person ingests 5,800 particles of plastic per year from beer, salt and tap water, with largest contribution coming from tap water (88\%) [10].

\section{3 and 10 tons of plastic fibers fall on Paris per year}

Microplastics and nano plastics in our oceans evaporate into the sky and in our atmosphere providing a source of both outdoor and indoor air pollution. A recent study investigating the atmospheric fallout of microplastics estimated between 3 and 10 tons of plastic fibers are fall on Paris per year [24].

\section{Evidence of Plastic in Humans}

\section{Biomonitoring programmes}

Biomonitoring human studies are evolving and useful for investigating exposure to phthalates, BPA and other chemicals. The National Health and Nutrition Examination Survey (NHANES) is conducted annually in US by the Centers for Disease Control and Prevention (CDC). One of the NHANEs study objectives is to analyse the number of POPs detected per person at high concentrations in the U.S. population. The NHANES state it may be relatively common for humans to have low and high concentrations of numerous POPs. In relation to plastic POPs the NHANEs study measures;

- $\quad$ Serum dioxins, furans and PCB

- $\quad$ Urinary phthalates and BPA [25]

One NHANEs study found 91 POPs analyzed in blood samples and concluded that one tenth of the US population may have $\geq 10$ POPs each at concentrations in the top decile [26].

\section{Plastic in human stools}

Nine different plastics have been found in all human stools tested [27].

\section{Latest Cause for Concern}

\section{Nanoplastic passes the BBB in fish}

Science has shown that nanoparticles or nano plastic passes the blood-brain barrier (BBB) in fish resulting in behavioural disorders and brain damage [28]. Most of the information we understand about the detrimental health effects of come from studies conducted in fish. The WHO is only just now looking into the health effects of plastics n humans.

\section{Main Text}

The WHO launched a health review on microplastics in drinking water to:

- $\quad$ Review the very scarce evidence

- Identify evidence gaps

- $\quad$ Establish research agenda

- Inform a more thorough risk assessment

\section{Endocrine Disrupting Chemicals (EDCs) and} Human Health

EDCS include organochlorine pesticides, PCBs, BPA, phthalates, dioxins and furans [29].

Close to 800 chemicals EDCs, capable of interfering with hormone;

- $\quad$ Receptors

- $\quad$ Synthesis

- Conversion

Three strands of evidence give strength to concerns over EDCs:

1. High incidence and increasing rates of endocrine-related disease in humans.

2. Observations of endocrine-related consequences in wildlife populations.

3. Laboratory studies linking EDCs and human health outcomes [30].

\section{EDC Diseases and Disorders}

I. Female and male infertility: BPA can interfere with hypothalamic-pituitary axis (HPA), such as increasing hypothalamic gonadotropin-releasing hormone (GnRH) secretion and promoting pituitary proliferation [31].

II. Low sperm count: In up to $40 \%$ of young men.

III. Genital malformations: Cryptorchidisms (nondescending testes) and hypospadias (penile malformations) in baby boys.

IV. Sharp increase in children born with intersex variation IV: Ambiguous genitalia, hermaphrodite, pseudohermaphroditism etc.

V. Sharp increase in gender dysphoria, transgender and gender neutral: Lesbian, Gay, Bisexual, Transgender, Queer or Questioning and Intersex (LGBTQI) existed pre-industrial revolution.

VI. Precocious puberty: In young girls (risk factor for breast cancer). 
VII. Adverse pregnancy outcomes: Preterm birth/low birth weight.

\section{Neurobehavioral disorders:}

- $\quad$ Cognitive, motor and sensory deficits.

- $\quad$ Neurological impairments (NIs) including neuropathies.

- Neurodevelopmental disorders (NDDs) autism and attention deficit hyperactivity disorder (ADHD).

- Neurodegenerative diseases (NDGs) including Alzheimer's disease, Parkinson's disease and amyotrophic lateral sclerosis (ALS).

- $\quad$ Exposure associated with POPs, plastic exudates BPA and phthalates [32].

IX. Hormone dependent tumours: Breast, endometrial, ovarian, prostate, testicular and thyroid.

\section{Metabolic disorders:}

- $\quad$ Polycystic Ovary Syndrome (PCOS).

- Metabolic syndrome: Evidence shows EDCs may contribute to the obesity pandemic evolution and metabolic disorders including Type 2 Diabetes (T2D) [33]. Lipophilic POPs linked to T2D [34].

XI. Atopic disorders: Phthalates and BPA exposure are associated with allergies, asthma and atopic dermatitis [35].

\section{Lowered vaccine response}

A study of two birth cohorts in the Faroe Islands, where diets may include whale blubber contaminated with PCBs, suggests exposure to PCBs may reduce immune response to childhood vaccinations [36]. Another study in Dutch preschool children measured humoral immunity by antibody levels for mumps, measles, and rubella after primary vaccination and found that prenatal PCB exposure measured as a higher dioxin toxic equivalent (TEQ) was associated with an increased number of lymphocytes, T-cells, and cluster of differentiation (CD) CD8+ (cytotoxic), CD4+ (memory), T-cell receptor (TcR) and CD3(+) (activated) T cells and lower antibody levels to mumps and measles at preschool age [37].

\section{Heath implications of microplastics according to the WHO}

It was widely reported recently that the WHO report referred to find no evidence of a current danger from microplastic [38]. This is not quite factual. In the first instance the WHO report is about micoplastics in drinking water only. Microplastics are as previously described ubiquitous. The WHO report in fact identified knowledge gaps and made recommendations in respect to monitoring and management of microplastics and plastics in the environment, and to better assess human health risks and inform appropriate management actions [39].

\section{Microplastic Mitigation}

- $\quad$ BPA and phthalates and dioxin-like PCBs are ingested plastic toxins.

- Dioxins and furans are inhaled plastic toxins produced when plastic is burned. Dioxins, furans and dioxin-like PCBs are abbreviated names for a family of chemicals with similar toxicity and shared chemical characteristics. Dioxins and furans are also known as Tetrachlorodibenzo-p-dioxin (TCDD), the contaminant in Agent Orange (herbicide used in the Vietnam War) [40].

\section{Mitigate Environmental Exposure}

Mitigation strategies include avoiding drinking water in plastic bottles and using an end stage water filtration unit to filter public drinking water supplies. Avoiding plastic incineration will also mitigate exposure. Phthalates are typically found in industrial solvents and lubricants, additives in the textile industry, in pesticides, floorings, roofing, wall coverings, cables, clothing, packaging materials, personal-care products and toys [41]. BPA is used in polycarbonate plastic and epoxy resins manufacture. BPAderived products used in safety equipment, baby bottles, protective coatings inside tin cans and as composites and sealants in dentistry. Exposure to BPA results primarily from ingesting contaminated food [42].

\section{Plastic Biotransformation}

\section{Measuring the burden of human exposure}

BPA-glucuronide has terminal half-life of $<6 \mathrm{~h}$, is rapidly excreted in urine and can be used as a biomarker of exposure to BPA. Exposure to these phthalates can be assess using custom synthesised reference standards of specific oxidised metabolites of Diisononyl phthalate (DINP) and Diisodecyl phthalate (DIDP). Phthalates are quickly metabolised and excreted in urine [43].

\section{What Happens After Exposure?}

After exposure, EDCs enter the body. Nano plastics reach the blood systemic circulation and distribute into various body compartments and penetrate cells [44]. Plastic too big to pass through gut wall still pose a risk as this plastic carries hydrophobic POPs /EDCs of smaller molecular size capable of penetrating cells [45].

\section{Understanding Biotransformation of Plastic}

Research into human biotransformation and elimination systems continue to evolve.

\section{Phase 1 and II Liver Detoxification Pathways}

Liver detoxification is a misnomer as Phase 1 and II Liver Detoxification Pathways also occur in kidney, intestine, lung, skin, prostate, and brain. In medical terminology toxicity is called bioaccumulation and detoxification is called biotransformation. Virtually no attention is paid human exposure to environmental 
chemicals and POPs in human beings. Many toxic chemicals are fatsoluble, making them difficult to excrete. The P450 enzyme system turns lipophilic (fat soluble) toxins into hydrophilic chemicals (water soluble) for excretion by via urine, bile and sweat. In event fat lipophilic toxins is not made hydrophilic, lipophilic chemicals have a high affinity for fat tissues and cell membranes. Toxins may be stored for years, being released during times of exercise, stress or fasting [46].

\section{Plastic Biotransformation}

\section{Bisphenol A}

Accumulation of BPA induces cytochrome P450 (CYP450) enzyme activities [47]. In humans BPA inhibits CYP17 activities and is mainly metabolised by CYP2C [48]. BPA is rapidly metabolised with glucuronidation conjugation [49]. BPA is also metabolite of sulphation and glutathione conjugation [50]. Transferases including sulfotransferases, glutathione-S-transferases (GSTs) are also involved in BPA conjugation [51]. A fraction of absorbed BPA may distribute to body storage site (s) such as adipose tissue, followed by a slow, low-level release of BPA into the bloodstream [43].

\section{Phthalates}

Phthalates undergo a series of phase I hydrolysis and phase II conjugation reactions and are subsequently excreted in faeces and urine [52]. Phthalates induce CYP450 [53] specifically CYP4 enzymes [54]. Phthalates are a metabolite of glucuronidation, [55, $56]$ glycine and sulphation conjugation [56, 57].

\section{Dioxins, furans and dioxin-like PCBs}

People vary in capacity to eliminate TCDD. The elimination rate is much faster at higher than lower levels [58]. TCDD induces a few CYP450 enzymes systems [59]. Accumulation of POPs, dioxins $[59,60]$ and furans induce cytochrome P450 enzyme systems [61]. Dioxins, furans and PCBs are metabolites of either glucuronidation or sulphate conjugation, mainly in the liver and excreted in the bile or urine [62]. Dioxins undergo glutathione [63] sulphation, [64] glucuronidation [40] and glycine conjugation phase II reactions [65].

\section{Phase I - Modification}

Phase I reactions occur in the liver and are catalyzed by CYP450 mixed-function oxidase enzyme (MFO) chemical reactions including oxidation, reduction, hydrolysis, cyclization, decyclization (cyclization and decyclization have no relevance in plastic biotransformation) and hydroxylation. MFO enzymes reside on the membrane system of the hepatocytes.

\section{Modification pathways involve:}

- Oxidation is process of being oxidised (combining chemically with oxygen/rust).
- Reduction involves gaining of electrons by one atom involved in reaction.

- Hydrolysis involves a chemical breakdown of a compound due to a water reaction.

- Hydroxylation involves introduction of a hydroxyl group $(-\mathrm{OH})[46]$.

\section{Induction of Phase I (over activity)}

Certain metabolites of Phase I reactions are readily excreted. Many Phase I products are not rapidly eliminated and undergo subsequent Phase II reactions. If not adequately supported or when excessive POPs exist, Phase I is induced producing high levels of damaging free radicals. If these reactive molecules are not metabolised by Phase II conjugation, damage to proteins, RNA, and DNA occurs. Phase I can turn a nontoxic molecule into a toxic (mutagenic/carcinogenic) molecule hence contribute to early ageing and cancer pathogenesis [66,67].

\section{Phase II - Conjugation}

In the hepatocytes toxic metabolites undergo biotransformation and are conjugated with glutathione (GSH), sulphate, glycine or glucuronic acid. These reactions are catalysed by a large group of broad-specificity transferases, the most important being glutathione S-transferases (GSTs). This makes the toxin or drug water-soluble, so it can then be excreted via bile, urine and sweat.

Major Phase II detoxification conjugation pathways include [46]

Glutathione (GSH): Co-factor: Glutathione and endogenous antioxidants; GlutathioneS-transferase (GST), superoxide dismutase (SOD), glutathione peroxidise (GPx), glutathione reductase (GR) and catalase (CAT) [68]. The glutathione S-transferases (GST family) are activated through cysteine, glutamic acid and glycine to make glutathione. BPA, [50] dioxins, furans and PCBs undergo glutathione conjugation [63].

Sulphation: $\quad$ Co-factor: $\quad 3$ '-phosphoadenosine-5'phosphosulfate (endogenously synthesised) Sulphation renders a xenobiotic less active but sometimes activates xenobiotics. Sulphation is involved in detoxification and hormone regulation. BPA, phthalates, [50,56,57] dioxins, furans [62,64] and PCBs undergo sulphation conjugation.

Glycine conjugation: Co-factor: Glycine is catalysed by glycine $\mathrm{N}$-acyltransferase is an important metabolic pathway responsible for maintaining adequate levels of free coenzyme A. Phthalates, $[56,57]$ dioxins [65], furans and PCBs undergo glycine conjugation.

Glucuronidation: Co-factor: Uridine diphosphate (UDP) UDPglucuronic acid Uridine diphsphate glucuronic acid (UDPGA). The enzyme $\beta$ glucuronidase breaks the bonds formed during the detoxification process, which allows substances to re-circulate in 
the body [69]. BPA, phthalates, $[49,55,56,70]$ dioxins, furans and PCBs [40] undergo glucuronidation conjugation [40].

\section{Phase II Conjugation Pathways Not Associated with Plastic Biotransformation}

Methylation: Co-factor: S-adenosyl-L-methionine (SAM-e). Heavy metals, arsenic, mercury, cadmium and DNA/RNA are biomethylated [71].

Acetylation: Co-factor: Acetyl-CoA (acetyl coenzyme A). $\mathrm{N}$-terminal Acetylation is catalysed by N-terminal acetyltransferases (NATs). NATs act as both onco-proteins and tumour suppressors in human cancers [72].

\section{Pharmacognostical objectives:}

- Inhibit CYP450

- Induce conjugation

\section{Andrographis/ Chuan Xin Lian/King of the bitters} Andrographis paniculata

The diterpenolactones andrographolide, 14-deoxy-11dehydroandrographolide, 14-deoxy-11- oxoandrographolide, 5-hydroxy-7,8,2',3'-tetramethoxyflavone, neoandrographolide, paniculide-A, paniculide-B and paniculide-C inhibit CYP450 [73].

\section{Bupleurum/Chai Hu Bupleurum falcatum}

The saikosaponins inhibit CYP450, specifically CYP1A2, CYP2C9 and CYP3A4. The flavonoids and steroids, rutin, isoquercetrin, isorhamnetin, quercetin, $\beta$-sitosterol, $\alpha$-spinasterol, daucosterol and $\alpha$-spinasterol glucoside inhibit CYP450 specifically CYP3A4 $[73,74]$.

\section{Burdock/Nui Bang Zi Arctium Lappa}

The lignans lappaol F, diarctigenin and arctigenin inhibit CYP450 [73].

\section{Centella/Ji Xue Cao Centella asiatica}

The triterpenes madecassic acid, brahmic acid and asiatic acid inhibit CYP450 [73].

\section{Eleutherococcus/Ci Wu Jia Eleutherococcus senticosus}

The glycans eleutherans A, B, C, D, E, F, and G and eleutheroside C inhibit CYP450 [73].

\section{Scut Baic/Huang Qin Scutellaria baicalensis}

The iridoid glycosides baicalein, wogonin and oroxylin inhibits CYP450 [73].

\section{Inhibit Phase I and Induce Phase II}

\section{Milk thistle silybum marianum}

The flavonolignans silymarin, silybin A, silybin B, isosilybin A, isosilybin B, silychristin, isosilychristin, silydianin, and one flavonoid taxifolin [75] significantly inhibits CYP450 [76]. Silymarin restores depleted GSH to assist in glutathione conjugation [77]. Milk thistle is rich in phytochemicals that can modulate UDPglucuronosyltransferase (UGT) Phase II enzymes [78].

\section{Globe artichoke/Yang Ji Cynara scolymus}

The flavonoid luteolin inhibits CYP450 specifically CYP 3A4 and CYP3A5 [79].

The hydroxycinnamic acid cynarin stimulates glucuronidation conjugation. Artichoke has potent antioxidant activity and reduces toxin-induced reduction of glutathione reserves [80].

\section{Barberry/Fu Niu Berberis vulgaris}

The benzylisoquinoline alkaloid berberine inhibits CYP450. [81] Berberine specifically increases endogenous antioxidants, glutathione peroxidase (GPx) and superoxide dismutase (SOD), both copper-zinc SOD (CuZn-SOD) and manganese SOD (Mn-SOD) to assist glutathione conjugation [82].

\section{Turmeric /Jiang Huang Curcuma longa}

The diarylheptanoid curcumin inhibits CYP450 whilst inducing Phase II $[83,84]$. Curcumin restores depleted GSH to assist glutathione conjugation [85]. Curcumin induces nuclear factorerythroid-2-related factor 2 (Nrf2), a leucine zipper (bZIP) protein that regulates expression of antioxidant proteins thereby protecting against oxidative damage triggered by injury and inflammation [86]. Phase-II enzymes are regulated by Nrf2. Curcumin modulates Phase I and Phase II enzymes [87].

\section{Supplements}

\section{$\mathrm{N}$-acetylcysteine}

$\mathrm{N}$-acetylcysteine (NAC) is a precursor to L-cysteine that results in GSH elevation biosynthesis. NAC increases GSH conjugation and is a powerful antioxidant/free radical scavenger [88].

\section{Caclium D-Glucarate}

Caclium D-Glucarate (CDG) inhibits $\beta$-glucuronidase, therefore enhances glucuronidation conjugation [89]. CDG is in cruciferous vegetables including cabbage, broccoli, brussel sprouts, cauliflower, radishes, watercress, turnips, collard greens and kale.

\section{Sulforaphane}

Sulforaphane (SFN), an isothiocyanate found in cruciferous vegetables inhibits CYP450 and induces Phase II [90].

\section{Hesperidin}

Hesperidin, a flavanone found in citrus fruits (oranges, lemons, pomelo), inhibits CYP450 and induces Phase II [91].

\section{Grapefruit}

Grapefruit contains the compound naringenin which inhibits CYP450 and induces Phase II [54]. 


\section{Conclusion}

As the awareness of microplastic contamination grows, so too does global concern regarding the health implications. Whilst reproductive and developmental abnormalities linked to EDC exposures in birds, frogs, seals, polar bears, marine mollusks, and other wildlife species are documented, the health effects of chemicals associated with full exposure from the whole gamut of endocrine-disrupting ability in humans including organochlorine pesticides, PCBs, BPA, phthalates, dioxins, and furans is yet to be ascertained, with the WHO report identified knowledge gaps. Some in the medical fraternity dismiss detoxification as quackery. What is true is that research into human biotransformation and elimination systems continues to evolve. Both mitigation strategies and research into pharmacognostical approaches that support biotransformation of POPs including dioxins, furans, BPA and phthalates is urgently needed. CAM therapists who specializes in bioaccumulation and biotransformation may have a valuable role to play in detoxifying harmful microplastic and nano plastic in human beings. Further research into this area is warranted and the results and applications of this research have the potential to reduce endogenous EDCs and POPs in humans and thus, have the potential to lead to improved global health outcomes.

\section{Acknowledgment}

None.

\section{Conflict of Interest}

Author has no conflict of interest.

\section{References}

1. Jennings MD (2003) Oil and war: we had the warning 30 years ago. Nature 423(6935): 15.

2. (2018) Office of the Assistant Secretary of Defense for Energy I, and Environment. Operational Energy.

3. (2018) Now near 100 million bpd, when will oil demand peak?

4. (2018) Plastic Production, UK.

5. Jambeck JR, Geyer R, Wilcox C, Siegler TR, Perryman M, et al. (2015) Marine pollution. Plastic waste inputs from land into the ocean. Science 347(6223): 768-771.

6. Brennecke D, Duarte B, Paiva F, Caçador I, Canning Clode J (2016) Microplastics as vector for heavy metal contamination from the marine environment. Estuarine, Coastal and Shelf Science 178: 189-195.

7. Munier B, Bendell LI (2018) Macro and micro plastics sorb and desorb metals and act as a point source of trace metals to coastal ecosystems. PloS one 13(2): e0191759.

8. Van A, Rochman CM, Flores EM, Hill KL, Vargas E, et al. (2012) Persistent organic pollutants in plastic marine debris found on beaches in San Diego, California. Chemosphere 86(3): 258-263.

9. Wong MH, Armour MA, Naidu R, Man M (2012) Persistent toxic substances: sources, fates and effects. Rev Environ Health 27(4): 207213.

10. Mary Kosuth Mason SA, Wattenberg EV (2018) Anthropogenic contamination of tap water, beer, and sea salt. Plos One 13(4): e0194970.

11. Mary Kosuth EVW, Sherri A, Mason, Christopher Tyree, Dan Morrison (2017) Synthetic polymer contamination in Global drinking Water.
12. Anne Marie, Mahon RO, Róisín Nash, Ian O'Connor (2014) Research 210: Scope, Fate, Risks and Impacts of Microplastic Pollution in Irish Freshwater Systems. EPA GMIT.

13. (2019) Morrison CTaD. Microplastics Found in Global Bottled Water. Orb Media.

14. Mason SA, Welch VG, Neratko J (2018) Synthetic Polymer Contamination in Bottled Water. Frontiers in chemistry 6: 407.

15. Hernandez LM, Xu EG, Larsson HCE, Tahara R, Maisuria VB, et al. (2019) Plastic Teabags Release Billions of Microparticles and Nanoparticles into Tea. Environ Sci Technol 53(21): 12300-12310.

16. Westerhoff P, Prapaipong P, Shock E, Hillaireau A (2008) Antimony leaching from polyethylene terephthalate (PET) plastic used for bottled drinking water. Water Res 42(3): 551-556.

17. Le HH, Carlson EM, Chua JP, Belcher SM (2008) Bisphenol A is released from polycarbonate drinking bottles and mimics the neurotoxic actions of estrogen in developing cerebellar neurons. Toxicology letters 176(2): 149-156.

18. Yang CZ, Yaniger SI, Jordan VC, Klein DJ, Bittner GD (2011) Most plastic products release estrogenic chemicals: a potential health problem that can be solved. Environmental health perspectives 119(7): 989-996.

19. Gallo F, Fossi C, Weber R, Santillo D, Sousa J, et al. (2018) Marine litter plastics and microplastics and their toxic chemicals components: the need for urgent preventive measures. Environ Sci Eur 30(1): 13.

20. Carney Almroth BM, Åström L, Roslund S, Petersson H, Johansson M, et al. (2018) Quantifying shedding of synthetic fibers from textiles; a source of microplastics released into the environment. Environ Sci Pollut Res Int 25(2): 1191-1199.

21. Napper I, Thompson R (2016) Release of synthetic microplastic plastic fibres from domestic washing machines: Effects of fabric type and washing conditions. Marine Pollution Bulletin 112(1-2): 39-45.

22. Marinković N, Pasalic D, Ferenčak G, Gršković B, Stavljenic-Rukavina A (2010) Dioxins and Human Toxicity. Arh Hig Rada Toksikol 61(4): 445453.

23. Anne Marie Mahon RO, Róisín Nash (2017) Ian O'Connor Scope, Fate, Risks and Impacts of Microplastic Pollution in Irish Freshwater Systems Marine and Freshwater Research Centre, Galway-Mayo Institute of Technology, Environmental Protection Agency, Galway, Ireland.

24. Dris R, Gasperi J, Saad M, Mirande C, Tassin B (2016) Synthetic fibers in atmospheric fallout: A source of microplastics in the environment? Mar Pollut Bull 104(1-2): 290-293.

25. (2010) Committee on Toxicity of Chemicals in Food Cpatec. National Health and Nutrition Examination Survey (Nhanes)

26. Pumarega J, Gasull M, Lee DH, López T, Porta M (2016) Number of Persistent Organic Pollutants Detected at High Concentrations in Blood Samples of the United States Population. PLoS One 11(8): e0160432.

27. Stephanie L, Wright FJK (2017) Threat to human health from environmental plastics. BMJ 358: j4334.

28. Mattsson K, Johnson EV, Malmendal A, Linse S, Hansson LA, et al. (2017) Brain damage and behavioural disorders in fish induced by plastic nanoparticles delivered through the food chain. Scientific reports 7(1): 11452.

29. Hood E (2005) Are EDCs blurring issues of gender? Environmental health perspectives 113(10): A670-A677.

30. Åke Bergman JJH, Susan Jobling, Karen A, Kidd R, Thomas Zoeller (2012) State of the Science of Endocrine Disrupting Chemicals Geneva: WHO UNEP Inter-organisation programme fro the sound managemnt of chemicals: A cooperative agreement among FAO, ILO, UNDP, UNEP, UNIDO, UNITAR, WHO, World Bank and OECD, Geneva, Switzerland.

31. Huo X, Chen D, He Y, Zhu W, Zhou W, et al. (2015) Bisphenol-A and Female Infertility: A Possible Role of Gene-Environment Interactions. Int J Environ Res Public Health 12(9): 11101-11116. 
32. Zeliger HI (2013) Exposure to lipophilic chemicals as a cause of neurological impairments, neurodevelopmental disorders and neurodegenerative diseases. Interdiscip Toxicol 6(3): 103-110.

33. Le Magueresse Battistoni B, Labaronne E, Vidal H, Naville D (2017) Endocrine disrupting chemicals in mixture and obesity, diabetes and related metabolic disorders. World J Biol Chem 8(2): 108-119.

34. Zeliger HI (2013) Lipophilic chemical exposure as a cause of type 2 diabetes (T2D). Rev Environ Health 28(1): 9-20.

35. Robinson L, Miller R (2015) The Impact of Bisphenol A and Phthalates on Allergy, Asthma, and Immune Function: a Review of Latest Findings. Current environmental health reports 2(4): 379-387.

36. Heilmann C, Grandjean P, Weihe P, Nielsen F, Budtz-Jørgensen E (2006) Reduced Antibody Responses to Vaccinations in Children Exposed to Polychlorinated Biphenyls. PLoS Med 3(8): e311.

37. Weisglas Kuperus N, Patandin S, Berbers GA, Sas TC, Mulder PG, et al. (2000) Immunologic effects of background exposure to polychlorinated biphenyls and dioxins in Dutch preschool children. Environ Health Perspect 108(12): 1203-1207.

38. Taylor AP (2019) Microplastics in Drinking Water Don't Threaten Human Health: WHO, Geneva, Switzerland.

39. (2019) WHO. Microplastics in drinking water, Geneva, Switzerland.

40. Bank PA, Salyers KL, Zile MH (1989) Effect of tetrachlorodibenzo-pdioxin (TCDD) on the glucuronidation of retinoic acid in the rat. Biochim Biophys Acta 993(1): 1-6.

41. David RH, McKee R, Butala JA, Barter R, Kayser M (2001) Esters of Aromatic Mono-, Di-, and Tricarboxylic Acids, Aromatic Diacids and Di-, Tri-, Or Polyalcohols.

42. Kang JH, Kondo F, Katayama Y (2006) Human exposure to bisphenol A. Toxicology 226(2-3): 79-89.

43. Koch HM, Calafat AM (2009) Human body burdens of chemicals used in plastic manufacture. Philos Trans R Soc Lond B Biol Sci 364(1526): 2063-2078.

44. Revel M, châtel A, Mouneyrac C (2018) Micro(nano)plastics: A threat to human health? Current Opinion in Environmental Science \& Health 1: 17-23.

45. Teuten EL, Saquing JM, Knappe DRU, Barlaz MA, Jonsson S, et al. (2009) Transport and release of chemicals from plastics to the environment and to wildlife. Philos Trans R Soc Lond B Biol Sci (1526): 2027-2045.

46. (2018) Drug metabolism.

47. Takeshita A, Koibuchi N, Oka J, Taguchi M, Shishiba Y, et al. (2001) Bisphenol-A, an environmental estrogen, activates the human orphan nuclear receptor, steroid and xenobiotic receptor-mediated transcription. Eur J Endocrinol 145(4): 513-517.

48. Niwa T, Fujimoto M, Kishimoto K, Yabusaki Y, Ishibashi F, et al. (2001) Metabolism and interaction of bisphenol A in human hepatic cytochrome P450 and steroidogenic CYP17. Biol Pharm Bull 24(9): 1064-1067.

49. Ginsberg G, Rice DC (2009) Does rapid metabolism ensure negligible risk from bisphenol A? Environ Health Perspect 117(11): 1639-1643.

50. Jaeg JP, Perdu E, Dolo L, Debrauwer L, Cravedi JP, et al. (2004) Characterization of new bisphenol a metabolite produced by CD1 mice liver microsomes and S9 fractions. J Agric Food Chem 52(15): 49354942.

51. Shmarakov IO, Borschovetska VL, Blaner WS (2017) Hepatic Detoxification of Bisphenol A is Retinoid-Dependent. Toxicol Sci 157(1): 141-155.

52. Frederiksen H, Skakkebaek NE, Andersson AM (2007) Metabolism of phthalates in humans 51(7): 899-911.

53. Takeshita A, Igarashi Migitaka J, Nishiyama K, Takahashi H, Takeuchi Y, et al. (2011) Acetyl Tributyl Citrate, the Most Widely Used Phthalate Substitute Plasticizer, Induces Cytochrome P450 3A through Steroid and Xenobiotic Receptor. Toxicol Sci 123(2): 460-470.
54. Hodges RE, Minich DM (2015) Modulation of Metabolic Detoxification Pathways Using Foods and Food-Derived Components: A Scientific Review with Clinical Application. J Nutr Metab 2015: 760689.

55. Stein TP, Schluter MD, Steer RA, Ming X (2013) Autism and phthalate metabolite glucuronidation. J Autism Dev Disord 43(11): 2677-2685.

56. Walter J, Crinnion JEP (2018) Clinical Environmental Medicine. Identification and Natural Treatment of Diseases Caused by Common Pollutants. Elsevier p. 97.

57. (2008) National Research Council (US) Committee on the Health Risks of Phthalates.Washington (DC): National Academies Press (US). Phthalates and Cumulative Risk Assessment: The Tasks Ahead.

58. Marinkovic N, Pasalic D, Ferencak G, Grskovic B, Stavljenic Rukavina A (2010) Dioxins and human toxicity. Arh Hig Rada Toksikol 61(4): 445453.

59. Schrenk D (1998) Impact of dioxin-type induction of drug-metabolizing enzymes on the metabolism of endo-and xenobiotics. Biochem Pharmacol 55(8): 1155-1162.

60. Kubota A, Watanabe MX, Kim EY, Yoneda K, Tanabe S, et al. (2012) Accumulation of dioxins and induction of cytochrome P450 1A4/1A5 enzyme activities in common cormorants from Lake Biwa, Japan: temporal trends and validation of national regulation on dioxins emission. Environ Pollut 168: 131-137.

61. Harrad S (2001) Persistent Organic Pollutants: Environmental Behaviour and Pathways of Human Exposure In: Harrad S (Ed.) West Sussex, UK.

62. Daidoji T, Gozu K, Iwano H, Inoue H, Yokota H (2005) UDPglucuronosyltransferase isoforms catalyzing glucuronidation of hydroxy-polychlorinated biphenyls in rat. Drug Metab Dispos 33(10): 1466-1476.

63. Odell GB, Mogilevsky WS, Smith PB, Fenselau C (1991) Identification of glutathione conjugates of the dimethyl ester of bilirubin in the bile of Gunn rats. Mol pharmacol 40(4): 597-605.

64. Dhakal K, He X, Lehmler HJ, Teesch LM, Duffel MW, et al. (2012) Identification of sulfated metabolites of 4-chlorobiphenyl (PCB3) in the serum and urine of male rats. Chem Res Toxicol 25(12): 2796-2804.

65. Tarloff JB, GRS, Hook JB (1987) Xenobiotic Metabolism in the Mammalian Kidney. In: Bach PH. LEA (Ed.) Springer, Dordrecht, Neatherlands.

66. Liska DJ (1998) The detoxification enzyme systems. Altern Med Rev 3(3): 187-198.

67. Omiecinski CJ, Vanden Heuvel JP, Perdew GH, Peters JM (2011) Xenobiotic metabolism, disposition, and regulation by receptors: from biochemical phenomenon to predictors of major toxicities. Toxicol Sci 120(1): S49-S75.

68. Pandey KB, Rizvi SI (2010) Markers of Oxidative Stress in Erythrocytes and Plasma During Aging in Humans. Oxid Med Cell Longev 3(1): 2-12.

69. Badenhorst CP, van der Sluis R, Erasmus E, van Dijk AA (2013) Glycine conjugation: importance in metabolism, the role of glycine $\mathrm{N}$-acyltransferase, and factors that influence interindividual variation. Expert Opin Drug Metab Toxicol 9(9): 1139-1153.

70. Fay MJ, Nguyen MT, Snouwaert JN, Dye R, Grant DJ, etal. (2015) Xenobiotic Metabolism in Mice Lacking the UDP-Glucuronosyltransferase 2 Family. Drug Metab Dispos 43(12): 1838-1846.

71. Tchounwou PB, Yedjou CG, Patlolla AK, Sutton DJ (2012) Heavy metal toxicity and the environment. Exp Suppl 101: 133-164.

72. Kalvik TV, Arnesen T (2013) Protein N-terminal acetyltransferases in cancer. Oncogene 32(3): 269-276.

73. Mohamed L, Ashour FSY, Haidy A Gad, Michael Wink (2016) Inhibition of Cytochrome P450 (CYP3A4) Activity by Extracts from 57 Plants Used in Traditional Chinese Medicine (TCM). Pharmacogn Mag 13(50): 300-308.

74. Yu T, Chen X, Wang Y, Zhao R, Mao S (2014) Modulatory effects of extracts of vinegar-baked Radix Bupleuri and saikosaponins on the activity of cytochrome P450 enzymes in vitro. Xenobiotica 44(10): 861-867. 
75. Polyak SJ, Morishima C, Lohmann V, Pal S, Lee DYW, et al. (2010) Identification of hepatoprotective flavonolignans from silymarin. Proc Natl Acad Sci U S A 107(13): 5995-5999.

76. Kawaguchi Suzuki M, Frye RF, Zhu HJ, Brinda BJ, Chavin KD, et al. (2014) The effects of milk thistle (Silybum marianum) on human cytochrome P450 activity. Drug Metab Dispo 42(10): 1611-1616.

77. Kim YC, Na JD, Kwon DY, Park JH (2018) Silymarin prevents acetaminophen-induced hepatotoxicity via up-regulation of the glutathione conjugation capacity in mice. Journal of Functional Foods 49: 235-240.

78. Mohamed ME, Frye R (2010) Effects of Herbal Supplements on Drug Glucuronidation. Review of Clinical, Animal, and In Vitro Studies. Planta med 77(4): 311-321.

79. Quintieri L, Palatini P, Nassi A, Ruzza P, Floreani M (2008) Flavonoids diosmetin and luteolin inhibit midazolam metabolism by human liver microsomes and recombinant CYP 3A4 and CYP3A5 enzymes. Biochem Pharmacol 75(6): 1426-1437.

80. Gebhardt R (1997) Antioxidative and protective properties of extracts from leaves of the artichoke (Cynara scolymus L.) against hydroperoxideinduced oxidative stress in cultured rat hepatocytes. Toxicol Appl Pharmacol 144(2): 279-286.

81. Guo Y, Chen Y, Tan ZR, Klaassen CD, Zhou HH (2012) Repeated administration of berberine inhibits cytochromes P450 in humans. Eur J Clin Pharmacol 68(2): 213-217.

82. Lao-ong T, Chatuphonprasert W, Nemoto N, Jarukamjorn K (2012) Alteration of hepatic glutathione peroxidase and superoxide dismutase expression in streptozotocin-induced diabetic mice by berberine. Pharm Biol 50(8): 1007-1012.

83. Muhammad I, Wang H, Sun X, Wang X, Han M, et al. (2018) Dual Role of Dietary Curcumin Through Attenuating AFB(1)-Induced Oxidative Stress and Liver Injury via Modulating Liver Phase-I and Phase-II Enzymes Involved in AFB(1) Bioactivation and Detoxification. Frontiers in pharmacology 9: 554 .

84. Krishnaswamy K, Goud VK, Sesikeran B, Mukundan MA, Krishna TP (1998) Retardation of experimental tumorigenesis and reduction in DNA adducts by turmeric and curcumin. Nutr Cancer 30(2): 163-166.

85. Jagatha B, Mythri RB, Vali S, Bharath MM (2008) Curcumin treatment alleviates the effects of glutathione depletion in vitro and in vivo: therapeutic implications for Parkinson's disease explained via in silico studies. Free Radic Biol Med 44(5): 907-917.

86. (2018) NFE2L2 protein that regulates the expression of antioxidant proteins.

87. Muhammad I, Wang H, Sun X, Wang X, Han M, et al. (2018) Dual Role of Dietary Curcumin Through Attenuating AFB1-Induced Oxidative Stress and Liver Injury via Modulating Liver Phase-I and Phase-II Enzymes Involved in AFB1 Bioactivation and Detoxification. Front Pharmacol 9:554.

88. Mokhtari V, Afsharian P, Shahhoseini M, Kalantar SM, Moini A (2017) A Review on Various Uses of N-Acetyl Cysteine. Cell J 19(1): 11-17.

89. Zoltaszek R, Kowalczyk P, Kowalczyk MC, Hanausek M, Kilianska ZM, et al. (2011) Dietary D-glucarate effects on the biomarkers of inflammation during early post-initiation stages of benzo[a]pyrene-induced lung tumorigenesis in A/J mice. Oncol Lett 2(1): 145-154.

90. Myzak MC, Dashwood RH (2006) Chemoprotection by sulforaphane: keep one eye beyond Keap1. Cancer let 233(2): 208-218.

91. Yahia EM (2017) Fruit and Vegetable Phytochemicals: Chemistry and Human Health, 2 Volumes. Wiley Blackwell, New Jersey p. 1012. 